\title{
Efficacy of Topical 1\% Oxiconazole Cream in the Treatment of Dermatophytosis
}

\author{
Md. Tawhidul Islam ${ }^{1}$, Shamima Akhter ${ }^{2}$, Lubna Khondker ${ }^{3}$, \\ Md Shirajul Islam Khan ${ }^{4}$, Ayesha Siddiqua ${ }^{5}$ \\ Received: October 1, 2013 Accepted: April 2, 2014
}

\begin{abstract}
Background: Dermatophytosis is a geographically widespread group of fungal infections. Tinea corporis and tinea cruris are the most common dermatophytoses in Bangladesh. Oxiconazole has recently been introduced in Bangladesh in the treatment of dermatophytoses. Objective: To evaluate the efficacy of topical 1\% oxiconazole cream once daily in the treatment of tinea corporis and tinea cruris. Materials and Methods: A clinical trial was carried out in the department of Dermatology and Venereology, Jalalabad Ragib-Rabeya Medical College Hospital, Sylhet on 81 patients with tinea corporis and/or tinea cruris. The patients were instructed to apply 1\% oxiconazole cream once daily for 2 weeks with clinical assessment made at weekly intervals during treatment period. Results: The mean age of the patients was $32.5 \pm 10.5$ years, with tinea corporis in $47(58.0 \%)$ patients and tinea cruris in $34(42.0 \%)$. The mean clinical assessment score declined from $6.6 \pm 1.3$ at baseline to $3.9 \pm$ 1.2 at week $1,0.9 \pm 1.3$ at week 2 and $0.7 \pm 1.1$ at week 4 . Reduction of clinical assessment score from baseline to end of the treatment period was statistically significant $(p<0.001)$. The improvement of clinical score was from baseline to $41.6 \%$ at week $1,89.3 \%$ at week 2 and 91.5\% at week 4. Improvement of clinical score from baseline to end of the treatment period was statistically significant $(p<0.001)$. Global response was clear in $55(67.9 \%)$ patients, good in 25 (30.9\%) patients and fair in 1(1.2\%) patient. Clinical efficacy was cure in 55 (67.9\%) patients, improvement in 25 (30.9\%) and failure in 1(1.2\%) patient. Conclusion: Once daily topical administration of oxiconazole cream is highly effective in the treatment of superficial fungal infections of the skin.
\end{abstract}

Key words: Dermatophytosis; Topical 1\% oxiconazole cream; Clinical assessment score

J Enam Med Col 2014; 4(2): 89-93

\section{Introduction}

Dermatophytosis is a geographically widespread group of fungal infections caused by dermatophytes. $^{1,2}$ Dermatophyte infections constitute a major public health problem in different countries. ${ }^{3-5}$ The climate, overcrowding, poverty, malnutrition, poor hygienic environments, endogenous predis- posing influences and ignorance are some of the contributory factors favourable for acquiring fungal infections in Bangladesh.6,7 Although not lifethreatening, they may produce significant symptoms which interfere with the quality of life. Tinea cruris and corporis are the commonest varieties and

1. Junior Consultant, Department of Dermatology and Venereology, Jalalabad Ragib-Rabeya Medical College \& Hospital, Sylhet

2. Professor, Department of Dermatology and Venereology, Jalalabad Ragib-Rabeya Medical College \& Hospital, Sylhet

3. Assistant Professor, Department of Dermatology and Venereology, Bangabandhu Sheikh Mujib Medical University (BSMMU), Dhaka

4. Graded Specialist in Dermatology and Venereology, Combined Military Hospital (CMH), Dhaka Cantonment, Dhaka 5. Specialist in Dermatology and Venereology, Bangabandhu Sheikh Mujib Medical University (BSMMU), Dhaka Correspondence Lubna Khondker, Email: lubnaderma@gmail.com 
aetiologically, T. rubrum tops the list followed by $T$. mentagrophytes and $E$. floccosun, $T$. verrucosum, $M$. canis and $M$. gypseum. ${ }^{8-10}$ Cutaneous dermatophytosis characteristically presents as scaly patches with central clearing and sharply demarcated, annular, erythematous, elevated, advancing margins. ${ }^{11}$ Oxiconazole nitrate is an imidazole antifungal agent recommended as an effective therapy for superficial fungal infections of the skin. ${ }^{12}$ It is fungistatic in action but may be fungicidal in high concentrations, presumably exerts its antifungal activity by altering cellular membranes, resulting in increased membrane permeability, secondary metabolic effects, and growth inhibition. ${ }^{13}$ It appears that the antifungal activity of the drug results from interference with ergosterol synthesis, probably via inhibition of C-14 methylation of sterol intermediates. ${ }^{14}$ Clinical study suggested that oxiconazole produced a clinical and mycologic cure within 2 to 4 weeks of initiating treatment. ${ }^{15}$ In comparative clinical trials of various types of dermatophytoses, oxiconazole was shown to be more effective than miconazole, clotrimazole, and tolnaftate creams, and as effective as econazole and bifonazole creams. ${ }^{16}$ Oxiconazole has recently been introduced in Bangladesh and no published data regarding the use of oxiconazole in the treatment of dermatophytosis in Bangladesh is yet available. So, this study was designed to evaluate the efficacy of once daily topical $1 \%$ oxiconazole cream in the treatment of tinea corporis and tinea cruris, the most common dermatophytosis.

\section{Materials and Methods}

A clinical trial was carried out with the patients with dermatophytosis attending the department of Dermatology and Venereology, Jalalabad RagibRabeya Medical College Hospital, Sylhet. Duration of the study was from January 2010 to October 2011. Patients of both sex aged 18 to 60 years, clinically diagnosed cases of tinea cruris and corporis infections and confirmed by a positive $\mathrm{KOH}$ reading were included. Patients with a history of hypersensitivity response to imidazole derivatives or any component of the formulation of oxiconazole cream, pregnant or lactating women, patients with renal or hepatic dysfunction, patients who received topical antifungal agents within the last week or received systemic antifungal agents within last four weeks and patients who refused to give consent were excluded. Sampling technique was consecutive type of non-probability sampling. Pre-designed data collection sheet was used to gather information.

\section{Procedure of the study}

Informed written consent was obtained from the patients after full explanation of the details of the disease process, options of treatment, ultimate outcome, possible side effects and complications and chances of recurrences and above all the purpose of the study. Eighty-one patients with tinea corporis and tinea cruris were selected according to the inclusion and exclusion criteria. Each and every patient was examined clinically as a diagnosed case of tinea corporis or cruris infections and confirmed by a positive $10 \% \mathrm{KOH}$ reading. The data collection sheet was filled up with the information including age, sex, occupation and socio-economic status. All patients were advised to apply oxiconazole $1 \%$ cream once daily for 2 weeks with clinical assessment made at weekly intervals during treatment period. Clinical and mycological $(10.0 \% \mathrm{KOH}$ reading) assessment were done following a two-week of non-treatment follow-up period (i.e., at the end of 4 weeks). Patients were evaluated clinically and mycologically $\left(10 \% \mathrm{KOH}\right.$ reading) at baseline and at $4^{\text {th }}$ week. The severity of signs and symptoms of tinea cruris or tinea corporis such as pruritus, erythema and burning were graded on a scale ranging from 0-3 (0.0, absent; 1.0, mild; 2.0, moderate; 3.0, severe). Global evaluation responses of the clinical condition compared to baseline were assessed in accordance to the following criteria. ${ }^{15}$

- Cleared: $100 \%$ remission of clinical signs and symptoms except for residual manifestations

- Excellent: 90-99\% improvement of clinical signs and symptoms from baseline

- Good: 50-89\% improvement of clinical signs and symptoms from baseline

- Fair: $25-49 \%$ improvement of clinical signs and symptoms from baseline

- Poor: $\leqslant 24 \%$ improvement of clinical signs and symptoms from baseline

- Worse: Clinical signs and symptoms deteriorated from baseline 
Clinical efficacy was categorised in the following way.

- Cure (disappearance of all baseline signs and symptoms of infection; negative $10 \% \mathrm{KOH}$ reading in conjunction with a global response as cleared or excellent)

- Improvement (partial disappearance of baseline signs and symptoms of infection)

- Failure (no change or worsening)

- Relapse (improvement or cure followed by reappearance or worsening)

\section{Statistical analysis}

Data were processed and analysed with the help of computer programme SPSS 16.0 version. Quantitative data were analysed using mean and standard deviation; qualitative data were analysed using rate, ratio and percentage. Repeated measure ANOVA was used for clinical assessment score and improvement of clinical score. A probability (p) value of $<0.05$ was considered statistically significant.

\section{Ethical consideration}

The protocol was approved by the Institutional Ethical Review Committee of Jalalabad RagibRabeya Medical College \& Hospital, Sylhet.

\section{Results}

This study was conducted on 81 patients with tinea corporis and tinea cruris who were instructed to apply oxiconazole $1 \%$ cream once daily for 2 weeks. The age of the patients ranged from 18 to 60 years with the mean age of $32.5 \pm 10.5$ years. The age of the male patients ranged from 18 to 60 years with the mean age of $33.4 \pm 11.4$ years while the age of the female patients ranged from 20 to 60 years with the mean age of $30.9 \pm 8.7$ years. The mean age of the female patients was significantly lower than that of male patients $(Z=1.114 ; p<0.05)$ (Table I).

Table I: Distribution of the patients by age and sex

\begin{tabular}{|l|c|c|c|}
\hline \multirow{2}{*}{ Sex } & \multicolumn{2}{|c|}{ Age (years) } & p value \\
\cline { 1 - 3 } & Range & Mean \pm SD & \\
\hline Male $(n=52)$ & $18-60$ & $33.4 \pm 11.4$ & \multirow{2}{*}{ Female $(n=29)$} \\
\hline Fem & $20-60$ & $30.9 \pm 8.7$ & $<0.05^{*}$ \\
\hline
\end{tabular}

*Z test was employed to analyse the data
Fig 1 shows the distribution of the patients by clinical types of dermatophytosis. Among 81 patients, tinea corporis was found in $47(58.0 \%)$ and tinea cruris in $34(42.0 \%)$ patients.

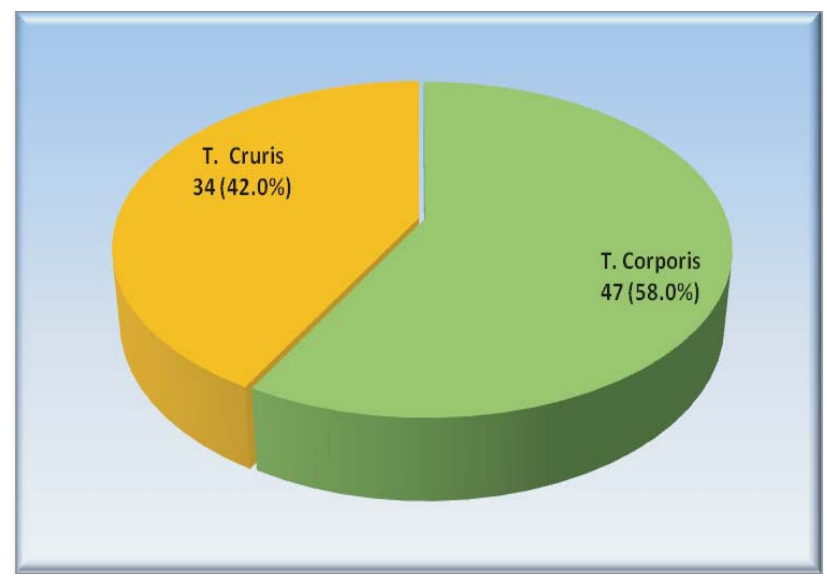

Fig 1. Distribution of the patients by clinical types of dermatophytosis $(\mathrm{n}=81)$

Fig 2 shows the clinical assessment score at different intervals. The mean clinical assessment score declined from $6.6 \pm 1.3$ at baseline to $3.9 \pm 1.2$ at week $1,0.9 \pm 1.3$ at week 2 and $0.7 \pm 1.1$ at week 4. Reduction of clinical assessment score from baseline to end of the treatment period was statistically significant $(p<0.001)$. Repeated measure ANOVA was employed to analyse the data.

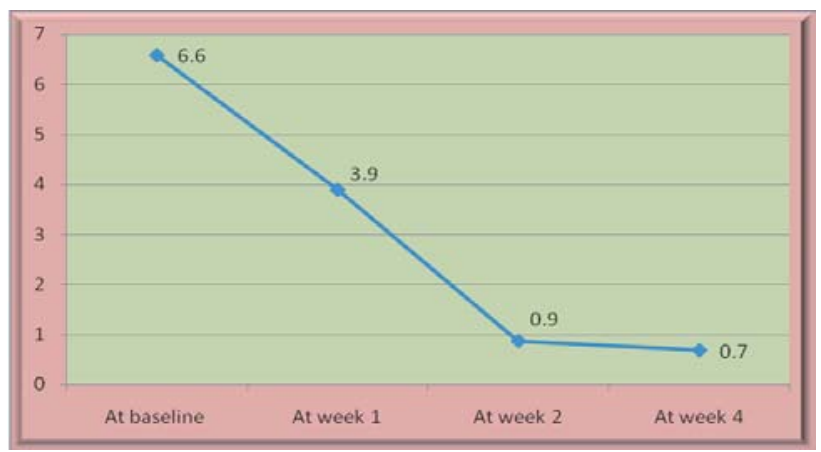

Fig 2. Clinical assessment score at different intervals $(n=81)$

Fig 3 shows the improvement at different time intervals. The improvement of clinical score was from baseline to $41.6 \%$ at week $1,89.3 \%$ at week 2 and $91.5 \%$ at week 4 . Improvement of clinical score from baseline to end of the treatment period was statistically significant $(\mathrm{p}<0.001)$. Repeated measure ANOVA was employed to analyse the data. 


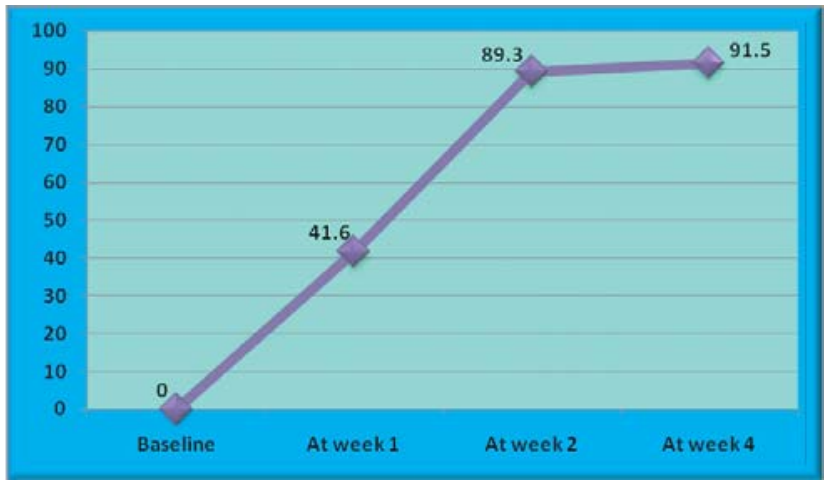

Fig 3. Improvement at different time intervals $(n=81)$

Distribution of patients by global response is shown in Fig 4. Global response was clear in $55(67.9 \%)$ patients, good in $25(30.9 \%)$ patients and fair in 1 $(1.2 \%)$ patient. Distribution of patients by clinical efficacy is shown in Fig 5. Clinical efficacy was cure in $55(67.9 \%)$ patients, improvement in $25(30.9 \%)$ patients and failure in $1(1.2 \%)$ patient.

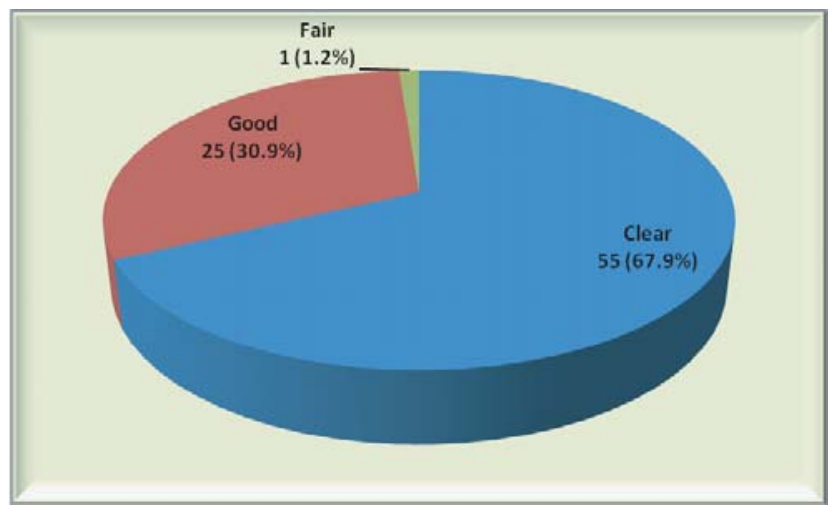

Fig 4. Distribution of patients by global response $(\mathrm{n}=81)$

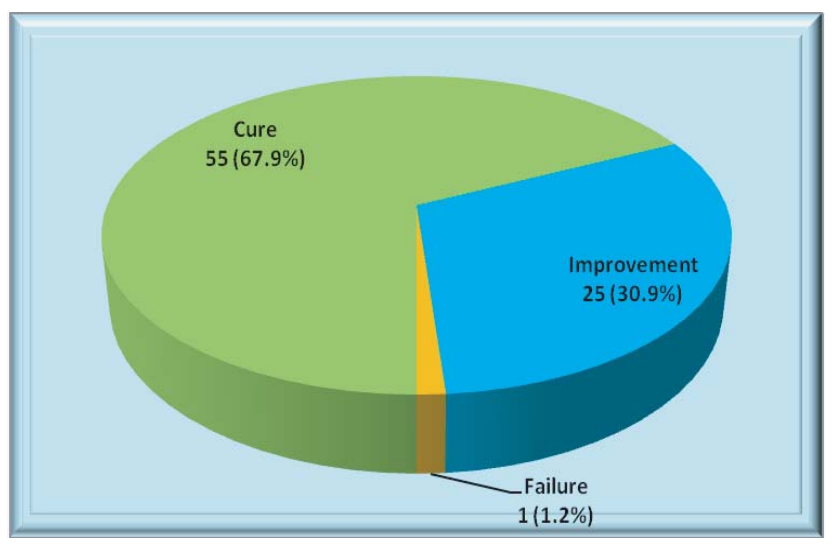

Fig 5. Distribution of patients by clinical efficacy $(n=81)$

\section{Discussion}

In this study the age of the patients ranged from 18 to 60 years with the mean age of $32.5 \pm 10.5$ years. This result was supported by Pakshir and Hashemi where mean age of the patients was 32 years. ${ }^{17}$ This study also showed that there were highest number of patients $(29,35.8 \%)$ in the age group of 21-30 years and this result was in concordance with the study of Patel et al where $58(29.30 \%)$ patients were in age group of 21-30 years. ${ }^{18}$

In the current study the mean clinical score declined from $6.6 \pm 1.3$ at baseline to $3.9 \pm 1.2$ at week $1,0.9 \pm 1.3$ at week 2 and $0.7 \pm 1.1$ at week 4 . Reduction of clinical assessment score from baseline to end of the treatment period was statistically significant $(p<0.001)$. Jerajani et al found that statistically significant $(\mathrm{p}<0.05)$ decline was observed by the end of one week treatment in respect of each of the signs/symptoms. ${ }^{19}$ The present study showed that improvement of clinical score was from baseline to $41.6 \%$ at week $1,89.3 \%$ at week 2 and $91.5 \%$ at week 4 . Improvement of clinical score from baseline to end of the treatment period was statistically significant $(\mathrm{p}<0.001)$. In this study the global response was clear in $55(67.9 \%)$ patients, good in $25(30.9 \%)$ patients and fair in $1(1.2 \%)$ patient. This result was supported by the study of Jerajani et al. ${ }^{19}$

In the current study the clinical efficacy was cure in $55(67.9 \%)$ patients, improvement in 25 (30.9\%) patients and failure in $1(1.2 \%)$ patient. Jerajani et al reported that once daily application of oxiconazole showed $81 \%$ cure rate which was comparable to twice daily application. ${ }^{19}$ Besides, the compliance with once daily application was found to be good. ${ }^{19}$ Gugnani et al reported that in most cases, oxiconazole produced a clinical cure within 2 to 4 weeks of initiating treatment. ${ }^{20}$

From this study, it can be concluded that once daily topical administration of oxiconazole cream is highly effective in the treatment of superficial fungal infections of the skin. However, multi-centred controlled randomised trial with large sample size should be carried out to draw final conclusion. 


\section{References}

1. Zaki SM, Ibrahim N, Aoyama K, Shetaia YM, AbdelGhany K, Mikami Y. Dermatophyte infections in Cairo, Egypt. Mycopathologia 2009; 167: 133-137.

2. Shy R. Tinea corporis and Tinea capitis. Pediatr Rev 2007; 28: 164-174.

3. Falahati M, Akhlaghi L, RastegarLari A, Alaghehbandan R. Epidemiology of dermatophytoses in an area south of Tehran, Iran. Mycopathologia 2003; 156: 279-287.

4. Woldeamanuel Y, Mengistu Y, Chryssanthou E, Petrint B. Dermatophytosis in Tulugudu Island, Ethiopia. Med Mycol 2005; 43: 79-82.

5. Thomas B. Clear choices in managing epidermal tinea infections. J Fam Pract 2003; 52(11): 850-862.

6. Maraki S, Nioti E, Mantadakis E, Tselentis Y. A 7year survey of dermatophytoses in Crete, Greece. Mycoses 2007; 50: 481-484.

7. Weinstein A, Berman B. Topical treatment of common superficial tinea infections. Am Fam Physician 2002; 65(10): 2095-2102.

8. Pariser DM, Pariser RJ. Oxiconazole nitrate lotion, 1 percent: an effective treatment for tinea pedis. Curis 1994; 54(1): 43-44.

9. Dahdah MJ, Scher RK. Dermatophytes. Current Fungal Infection Reports 2008; 2: 81-86.

10. Gupta AK, Cooper EA. Update in antifungal therapy of dermatophytosis. Mycopathologia 2008; 166: 353-367.

11. Rahman AKMM, Rahman MM, Haque MA. Dermatophytoses: a study of northern area of
Bangladesh. Northern Medical Journal 2010; 9(2): 91-95.

12. Hay RJ, Ashbee HR. Mycology. In: Burns T, Breathnach S, Cox N, Griffiths C (eds). Rook's textbook of dermatology. $8^{\text {th }}$ edn. Oxford: WileyBlackwell Publisher, 2010: 36.1-36.93.

13. Wu SX, Shen YN, Yan N, Guo NR, Liu LL, Yang JQ. Experimental and clinical investigation on oxiconazole. Chin Med J 1989; 102(8): 644-646.

14. Ramelet AA, Walker-Nasir E. Once daily application of oxiconazole cream is sufficient for treating dermatomycoses. Dermatologica 1987; 175(6): 293-295.

15. Gip L. Comparison of oxiconazole and econazole in dermatomycoses. Mykosen 1984; 27: 295-302.

16. Jegasothy BV, Pakes GE. Oxiconazole nitrate: pharmacology, efficacy, and safety of a new imidazole antifungal agent. Clin Ther 1991; 13(1): $126-141$.

17. Pakshir K, Hashemi J. Dermatophytosis in Karaj, Iran. Indian J Dermatol 2006; 51: 262-264.

18. Patel P, Mulla S, Patel D, Shrimali G. A study of superficial mycosis in South Gujarat region. National J Com Med 2010; 1(2): 85-88.

19. Jerajani HR, Amladi ST, Bongale R, Adepu V. Evaluation of clinical efficacy and safety of once daily topical administration of $1 \%$ oxiconazole cream and lotion in dermatophytosis: an open label, noncomparative multicentre study. Indian J Dermatol Venereol Leprol 2000; 66: 188-192.

20. Gugnani HC, Ideyi C, Gugnani MK. Oxiconazole in the treatment of tropical dermatomycoses. Current Theraputic Research 1993; 54(1): 122-125. 